XXIV. Aus dem städtischen Krankenhause Moabit in Berlin.

\title{
Entgegnung auf die Mittheilung über Tuberkelbacillen im Blut nach Koch'schen Injectionen.
}

Von Direktor Dr. Paul Guttmann und Prof. Dr. Paul Ehrlich.

In der Berliner klinischen Wochenschrift (No. 4, 1891) hat Dr. Liebmann am Bürgerspital in Triest die Mittheilutio gemacht; dass er bei 8 mit Koch'schen Injectionen behandelten Tuberculösen im Blute Tuberkelbacillen (in kleiner Anzahl) gefunden habe, während dieselben in Controllversuchen bei nicht mit $\mathrm{Koch}$ 'schen Injectionen behandelten Tuberculösen im Blute nicht nachweisbar waren.

Wir haben diese Untersuchungen an 29 mit Koch'schen Injectionen behandelten Lungentuberculösen wiederholt. Das Blut wurde in gleicher Weise, wie in den Liebmann'schen Angaben, aus einer Fingerstichwunde unter den üblichen Cautelen entnommen, und zwar während des fieberhaften Reactionsstadiums am selben Abend nach der am Morgen stattgefundenen Injection, in einer anderen Zahl von Fällen 24 Stunden nach der Injection bei meistentheils noch vorhandenem Fieber, endlich auch in einigen Fällen 2-3 Tage nach der Injection bei mässig hoch fiebernden Kranken. Die Blutpräparate wurden unmittelbar darauf nach den bekannten Methoden gefärbt, bei einer Anzahl von Kranken je 2 Präparate, bei andern je eins. Jedes Präparay wurde, da es sich nach den Liebmann'schen Angaben nur um wenige Bacillen in einem Präparat handeln konnte, zur Sicherstellung des Urtheils mindestens von 2 Untersuchern, ein grosser Theil der Präparate aber wurde von inehreren Untersuchern durchgeprüft. Das Frgebniss war durchaus negativ; in keinem einzigen Präparate wurden Tuberkelbacillen gefunden. Auch Ewald hat in einer Anmerkung zu der Liebmann'schen Mittheilung erwähnt, dass er bei Wiederholung dieser Versuche ein negatives Ergebniss erhielt.

Es ist selbstverständlich, dass wir darauf verzichten müssen, die 29 untersuchten Fälle hier aneinander zu reihen; wir wollen nur im allgemeinen erwähnen, dass die Anzahl der Injectionen in den 29 Fällen zwischen 3 und 45 beträgt, die letzte Injectionsmenge zwischen 1 und $100 \mathrm{mg}$, die Temperatur - abgesehen von 3 unter $380 \mathrm{C}$ - zwischen 38,1 und $40,4^{\circ} \mathrm{C}$, und dass es sich bei allen diesen Kranken um sehr ausgesprochene Lungentuberculose, meistens auch mit dem Nachweise von Tuberkelbacillen im Sputum handelt. 